\title{
Políticas públicas para as comunicações no Brasil: adequação tecnológica e liberdade de expressão*
}

\author{
Octavio Penna Pieranti** \\ Paulo Emílio Matos Martins***
}

\begin{abstract}
Sumário: 1. Introdução; 2. Metodologia; 3. Parâmetros para o debate sobre políticas públicas para as comunicações; 4. A infra-estrutura para as comunicações no Brasil; 5. A regulação da liberdade de expressão no regime militar; 6 . A nova compreensão da liberdade de expressão; 7. Considerações finais.
\end{abstract}

Summary: 1. Introduction; 2. Methodology; 3 . Guidelines for the debate on communications public policies; 4. Communications infrastructure in Brazil; 5. Free speech regulation during the military regime; 6 . The new understanding of free speech; 7. Final remarks.

Palavras-chave: políticas públicas; imprensa; radiodifusão.

KEY WORDs: public policies; the press; broadcasting.

Pouco se tem debatido, no campo da pesquisa acadêmica em administração, as políticas públicas para as comunicações no Brasil. Este artigo analisa essas políticas de acordo com uma perspectiva histórica a partir de 1964 até o presente, utilizando como fonte trabalhos acadêmicos, não-acadêmicos e o manancial legal existente. Tem como focos, dentro do âmbito das comunicações, a radiodifusão e a mídia impressa. A análise foi feita com base em princípios e postulados tidos como essenciais: ao funcionamento do setor, como a independência da imprensa em relação ao Estado; a

\footnotetext{
* Artigo recebido em set. 2006 e aceito em jul. 2007.

** Doutorando em administração pela Escola Brasileira de Administração Pública e de Empresas da Fundação Getulio Vargas (Ebape/FGV), mestre em administração pública pela mesma instituição e jornalista formado pela Universidade Federal do Rio de Janeiro (UFRJ). Endereço: Praia de Botafogo, 190, sala 515 - CEP 22250-900, Rio de Janeiro, RJ, Brasil. E-mail: octavio. pieranti@fgv.br.

*** Professor titular da Escola Brasileira de Administração Pública e de Empresas da Fundação Getulio Vargas (Ebape/FGV), doutor em administração pela Escola de Administração de Empresas de São Paulo, da Fundação Getulio Vargas (Eaesp/FGV) e coordenador do Programa de Estudos de Administração Brasileira. Endereço: Praia de Botafogo, 190, sala 515 - CEP 22250-900, Rio de Janeiro, RJ, Brasil. E-mail: paulo.martins@fgv.br.
} 
interesses privados e a participação que esse ator tem na formação da infra-estrutura necessária às comunicações. Assim, o debate se divide em duas dimensões originais: a tecnológica, referente à montagem da infra-estrutura existente; e a informacional, dependente da regulação da liberdade de expressão pelo Estado. As considerações finais apontam para o caráter questionável da independência da mídia brasileira; a vinculação entre atores e interesses públicos e privados; e a confusão proposital entre liberdade de imprensa e de empresa.

\section{Communications public policies in Brazil: technological adjustment and free speech}

Brazilian researchers in the administration field seldom debate communications policies. This article analyzes these policies in a historical perspective from 1964 to our days, using as sources academic and non-academic literature and the existing legislation. It focuses the broadcasting system and the press, based on principles and postulates considered essential to this sector, such as the independence of the press in relation to the state and its interests and participation in the construction of the communications infrastructure. This debate is divided in two original dimensions: technological, referring to the existing infrastructure, and informational, dependent on State regulation of free speech. The article concludes by calling attention to: the questionable character of the Brazilian media's independence; the ties between public and private actors and interests; and the intentional confusion between free press and free corporations.

\section{Introdução}

Políticas públicas e comunicações não são termos freqüentemente associados na pesquisa acadêmica brasileira no campo da administração. Tradicionalmente é instável a regulação da mídia pelo Estado, oscilando entre o autoritarismo e a coerção e o simples não-estabelecimento de regras. A análise das políticas públicas nesse cenário ganha complexidade, tendo em vista que público e privado, no âmbito das comunicações, nem sempre podem ser diferenciados, seja por se tratar essa de uma atividade que, mesmo no âmbito privado, enfoca atores públicos, seja pela participação, no contexto brasileiro, de atores do setor público-estatal na gestão dessa atividade privada.

Este artigo debate as políticas públicas voltadas para as comunicações no Brasil a partir de 1964, ano de instauração do regime militar. O corte temporal proposto se explica pelas mudanças por que passaram as comunicações a partir daquele ano. Ainda que o principal marco de regulação da radiodifusão e da telefonia (o Código Brasileiro de Telecomunicações) tenha sido promulgado em 1962, os militares procederam a uma ampla reformulação do manancial legal existente, bem como da infra-estrutura voltada às comunicações. Findo o regime militar, a redemocratização do país promoveu reformas 
parciais tanto da legislação em vigor, quanto da infra-estrutura disponível. Assim, o regime iniciado em 1964 pode ser encarado como ponto de partida para o entendimento do presente e das políticas para as comunicações, seja por seu caráter formador das novas estruturas, seja pelo contraponto em que se constituiu para o legislador de 1988. Note que são focos centrais aqui as políticas públicas voltadas à imprensa e à radiodifusão. Questões relativas à telefonia e à transmissão de dados são debatidas quando essenciais à compreensão desses outros setores, sendo, porém, secundárias para o objetivo aqui delimitado.

A dificuldade em se discutir políticas públicas para as comunicações não se restringe ao pequeno número de pesquisas acadêmicas voltadas para o tema. Mesmo a terminologia que envolve essa problemática é confusa. Algumas fontes utilizadas referem-se à política nacional de comunicações e outras à política de comunicações - em ambos os casos, portanto, referem-se a algo único, não fragmentado e consolidado no âmbito nacional. Outras fontes sequer se referem a uma política específica, por acreditar que a ação do Estado nesse setor deve ser mínima. Neste artigo optamos pela terminologia políticas públicas, já que, ao longo da pesquisa, não foi possível constatar a existência de uma só política nacional, mas também foi reconhecida a ação do Estado, por vezes decisiva, no setor.

Na próxima seção, é apresentada a metodologia utilizada na pesquisa. A seguir, buscamos debater preceitos e postulados que orientam a formulação de políticas públicas para as comunicações — notadamente para a radiodifusão e para a imprensa. Depois, a análise recai sobre questões relativas à montagem da infra-estrutura necessária às comunicações. A regulação da liberdade de expressão precede as considerações finais.

\section{Metodologia}

A metodologia de investigação aqui é a historiográfica, cujos alicerces, no tocante à pesquisa em administração, são debatidos, entre outros autores, por Curado (2001), Martins (2001) e Vergara (2005). A primeira autora defende a utilização do paradigma de nova história como sustentáculo da pesquisa historiográfica voltada para a administração. De acordo com esse paradigma, a história diz respeito a todas as atividades humanas e essa não é uma mera narrativa dos acontecimentos, mas sim, uma análise das estruturas. Como lembra Vergara (2005), à historiografia não basta a análise das estruturas, é preciso que essas sejam interpretadas, de modo que não se repita uma simples 
narrativa dos acontecimentos — paradigma, de acordo com Curado (2001), da história tradicional.

Martins (2001) vai além na distinção entre os dois paradigmas de pesquisa de cunho histórico. O autor lembra que, até o século XIX, predominava a narrativa linear, cujos cânones eram os eventos conjunturais, curtos períodos temporais, acontecimentos políticos e personagens de notória relevância. Já no século XX ganhou força a interpretação que coloca como centro da historiografia aspectos econômicos e sociais, estruturas duradouras e os comportamentos coletivos de toda a sociedade.

Seguimos, neste artigo, as diretrizes referentes à nova história (nas palavras de Curado) e à história total (segundo Martins), mas não foram descartados princípios tidos como fundamentais pelo paradigma anterior. São centrais para a argumentação aqui desenvolvida a interpretação dos fatos e a análise das estruturas duradouras. Por outro lado, o domínio político, por sua excelência para as comunicações no Brasil, adquire a primazia desta análise, bem como são importantes observações referentes a eventos conjunturais.

A pesquisa aqui desenvolvida é bibliográfica e documental. São usados como referências principais livros, artigos publicados em jornais, revistas e sites na internet, marcos legais e transcrições de palestras.

A opção pela conjugação de textos acadêmicos e não-acadêmicos decorre de diversos fatores. É importante lembrar que o arquivamento de documentos históricos, no Brasil, nem sempre é preciso. Isso cria uma lacuna no que se refere a determinados acontecimentos importantes para a compreensão das estruturas vigentes. Documentos oficiais - notadamente aqueles que não se relacionam ao âmbito legal — constantemente não são preservados, com a compreensão das estruturas feita apenas por meio de palestras e material jornalístico. As primeiras têm riqueza principalmente em relação a versões oficiais, já os segundos são especialmente importantes para uma melhor contextualização dos fatos tratados e pela contemporaneidade dos temas discutidos.

A imprensa e a radiodifusão são temas de natural afinidade com a administração pública. $\mathrm{O}$ estudo de políticas públicas nesses campos está ligado à defesa das instituições democráticas, e é regulado por organizações oficiais no plano federal. A ação dos meios de comunicação de massa incide diretamente no funcionamento do aparelho de Estado - tanto em seu âmbito burocrático, quanto no político - , constituindo canal para a transmissão de anseios e críticas aos membros do governo. A importância da mídia para uma compreensão mais apurada da sociedade encontra óbvias evidências empíricas: como negar, por exemplo, os efeitos decorrentes da ação dos meios de comunicação em eleições ou nos debates de grandes questões públicas? É digna de nota, por- 
tanto, a inexistência de amplo debate sobre esse tema no campo da administração. Amplo debate, aliás, é eufemismo para a situação que de fato se configura: o número de artigos acadêmicos publicados sobre o tema é ínfimo.

Nas últimas 10 edições do Encontro da Associação Nacional de PósGraduação e Pesquisa em Administração (Enanpad), na área de administração pública - eventualmente dividida em gestão pública, políticas públicas e gestão social - foram apresentados 533 artigos (em média mais de 50 por ano). Apenas dois, ambos de 2005, tinham como foco a mídia brasileira, mas nenhum deles versou sobre políticas para esse setor ou sobre a relação entre as empresas de comunicação e o Estado. No I Encontro de Administração Pública e Governança, realizado em 2004, foi encontrado um único trabalho nessa linha, o de Pieranti (2004).

Situação semelhante ocorre em relação à Revista de Administração Pública (RAP), publicada pela Fundação Getulio Vargas desde 1967. Em 38 anos, esta publicação, que já foi semestral, trimestral e, desde 1996, é bimestral, teve mais de 160 edições, reunindo mais de mil artigos. Em nenhum desses 38 anos foi publicado qualquer trabalho sobre os meios de comunicação de massa sob a mesma perspectiva da análise feita em relação ao Enanpad.

A ausência de debate acadêmico nesse campo não se restringe ao Brasil. A revista bimensal norte-americana Public Administration Review, por exemplo, é ainda mais antiga que a $R A P$, publicada desde a década de 1940. Nesses mais de 60 anos da publicação, só foi possível encontrar um trabalho (uma transcrição de palestra), de uma edição da década de 1950, que remetia à relação entre imprensa e Estado. Por não oferecer acréscimos a este artigo, não foi utilizado.

$\mathrm{Na}$ ausência de amplo referencial teórico, que leva a uma lacuna histórica sobre os meios de comunicação de massa no campo da administração pública, buscamos trabalhos originalmente produzidos por autores ligados a outras ciências sociais e humanas. Recorremos à comunicação social, à história, às ciências políticas e à sociologia e, principalmente, por acreditarmos na interdisciplinaridade dessas áreas, em conformidade com os princípios da metodologia adotada tal como entendida na contemporaneidade, a trabalhos que, de alguma forma, se caracterizassem pela triangulação de condicionantes comuns.

\section{Parâmetros para o debate sobre políticas públicas para as comunicações}

Quando a Comissão Internacional para o Estudo dos Problemas da Comunicação da Unesco se reuniu pela primeira vez, em dezembro de 1977, os países 
latino-americanos estavam, em sua maioria, imersos em regimes ditatoriais, alguns dos quais já começavam a dar sinais de desgaste. O documento final, produzido pela comissão e apelidado de Relatório MacBride, em homenagem ao presidente da comissão, o jurista irlandês Sean MacBride, refletia a missão grandiosa proposta pela Unesco: "estudar a totalidade dos problemas da comunicação nas sociedades modernas".

As políticas públicas para as comunicações, de acordo com as conclusões da comissão da Unesco, estão relacionadas essencialmente ao modelo de desenvolvimento adotado por cada nação. Em um primeiro momento, a comunicação é vista como processo técnico, conseqüência do estabelecimento de infra-estrutura necessária para a transmissão de dados (Unesco, 1983:340):

O problema fundamental consiste na relação que se deve estabelecer entre a comunicação - obras de infra-estrutura e atividades - e os objetivos nacionais ou, em outras palavras, a incorporação do desenvolvimento da comunicação aos planos de desenvolvimento geral. Como a comunicação não é um setor separado e autônomo, a interdependência, talvez mais marcada nesse campo e em outros, impõe a necessidade de formular algumas políticas de comunicação que não se limitem à informação e ainda menos aos meios de comunicação social, mas sim que levem em consideração todos os meios que pode utilizar uma sociedade para atingir seus objetivos gerais de desenvolvimento.

Ao vincular as políticas públicas para as comunicações aos planos de desenvolvimento e aos objetivos nacionais, o relatório sugere a importância do Estado como peça-chave nesse processo. A construção da infra-estrutura, voltada principalmente para a radiodifusão, para a telefonia e para sistemas outros de transmissão de dados, demanda investimentos, em parte estatais, bem como reconhecimento por parte do Estado de que as comunicações são fundamentais para a estratégia de desenvolvimento a ser adotada. Nos países periféricos, segundo o documento, a ação do Estado é a maneira principal de se criar a infra-estrutura necessária às comunicações, seja por causa da carência de recursos para altos investimentos na incipiente iniciativa privada, seja por questões de foro ideológico.

Ressaltemos aí que a montagem da infra-estrutura necessária às comunicações é intensiva em capital e cara em tecnologia de ponta. Se, até a década de 1980, estava em pauta nos países em desenvolvimento o investimento em questões como transmissão via satélite, atualmente os gastos voltam-se para sistemas de transmissão digital de som e imagem. É essa, portanto, a primei- 
ra dimensão das políticas públicas para as comunicações, tal como debatidas pela Unesco - a relativa à infra-estrutura.

Políticas públicas para as comunicações não podem, contudo, se restringir à criação de infra-estrutura e a investimentos a ela vinculados. São de responsabilidade delas as condições para a difusão de idéias, aliadas ao já mencionado processo técnico de transmissão de informações. Para a Comissão Internacional para o Estudo dos Problemas da Comunicação da Unesco, o contexto jurídico, consideradas aí não apenas as leis, mas também a garantia, na prática, de direitos fundamentais delas decorrentes, deve assegurar o pluralismo e as condições para que a sociedade tenha à disposição fontes de informação e de idéias diversas e para que possa escolher livremente entre elas. A segunda dimensão das políticas públicas para as comunicações refere-se, portanto, ao grau de liberdade de expressão no contexto nacional. Dahl (2001) corrobora esse posicionamento, ao frisar que liberdade de expressão e acesso a fontes variadas de informação são duas das seis instituições fundamentais à poliarquia, modelo de democracia desenvolvido pelo autor.

Como frisa o Relatório MacBride, o Estado, por meio do Poder Judiciário ou de seu equivalente, é o responsável por garantir a liberdade de imprensa, derivada da liberdade de expressão, e a existência de múltiplas fontes de informação, sendo esse princípio muitas vezes violado.

A formulação da política de comunicação se baseia normalmente numa legislação nacional, que às vezes tem caráter constitucional e geral, e outras vezes é mais detalhada e específica. Liberdade e crença de opinião, de palavra, de expressão, de imprensa. Uma vez proclamadas, essas liberdades, sujeitas ou não a deveres, e acompanhadas ou não de garantias relativas aos meios materiais necessários para o seu exercício segundo os países, provocam, entretanto, algumas limitações que podem ser mínimas ou, pelo contrário, abarcar diversos aspectos relacionados com o seu exercício. Mas, às vezes, seria errôneo atribuir importância excessiva às disposições constitucionais, já que esses textos solenes costumam se revestir de caráter meramente formal e são apenas simples declarações de intenção ou princípios.

(Unesco, 1983:345).

A liberdade de expressão não depende apenas de uma legislação consoante com os princípios da poliarquia enumerados por Dahl. Por mais que seja garantida por legislação apropriada, ela é limitada por contingências político-sociais, tais como o esforço e o interesse de cada governo em permitir o funcionamento de instituições e a vigência de princípios ligados à poliarquia e dissociados da máquina estatal, já que, como lembra a Unesco, as políticas a 
serem adotadas em cada país para as comunicações são diretamente afetadas pelo grau de liberdade de expressão de que dispõe a sociedade. Encontramse essas políticas intimamente ligadas ao grau de liberdades experimentadas pela sociedade, porque, a julgar pelo relatório da Unesco, o ambiente democrático se reflete também nos meios de comunicação, valendo consignar, como já referido anteriormente, que a liberdade de imprensa nada mais é que a extensão da liberdade de expressão, direito fundamental de toda a sociedade, assim garantido nas constituições de diversos países. De acordo com a Unesco, em posicionamento ecoado por autores como Wheeler (1997), Kunczik (2002) e Kovach e Rosenstiel (2003), os jornalistas são vitais para a existência de uma opinião pública informada, de acordo com preceitos democráticos, ao resguardar o direito de a sociedade receber informações. Aceita essa função, a imprensa é caracterizada de distintas formas, como, por exemplo, "cão de guarda público" (Wheeler, 1997) e monitor independente do poder (Kovach e Rosenstiel, 2003).

Esse conceito é essencial aos meios de comunicação de massa. A liberdade de imprensa pressupõe não apenas a liberdade de informar independentemente das idiossincrasias e ações dos membros da administração pública, como também a independência em relação a interesses privados. Consagrado esse postulado, não se ignoram críticas quanto à sua validade na prática. Herman e Chomsky (2003) demonstram ceticismo ao tratar da independência da imprensa, lembrando que o jornalismo contemporâneo estrutura-se de acordo com a lógica empresarial e necessariamente subjugando-se, portanto, a interesses privados nem sempre compatíveis com os públicos.

Vale ressaltar que "interesse público" é conceito permanentemente associado aos meios de comunicação de massa. Via de regra, inclusive para os autores citados anteriormente, é central para o jornalismo a defesa desses interesses, visto que a imprensa se constitui em catalisador de demandas no âmbito público, papel que, para Kunczik (2002), é ainda mais ressaltado em países em desenvolvimento. Uma imprensa atrelada a interesses específicos de grupos privados, logo incapaz de defender exclusivamente o interesse público, segundo essa lógica, implicaria fechamento de um canal para a manifestação de demandas da sociedade e na ausência de uma instituição eficiente na comunicação entre governos e governados.

Ao abordar o conflito entre interesses públicos e privados, Arbex Júnior (2001) aponta a confusão entre a liberdade de imprensa e a de empresa. O primeiro conceito refere-se a uma liberdade pública, fruto de conquistas em ambiente democrático, não podendo ser privatizado, ou seja, interpretado 
como bem de empresas específicas. Em geral, porém, segundo o autor, a liberdade de imprensa é discutida como se fosse o direito que os empresários do setor têm de transmitir informações que julgam ser de interesse. Essa, porém, é a liberdade de empresa, vinculada às idiossincrasias de pessoas específicas. Mais ampla, a liberdade de imprensa, como enfatiza também o relatório da Unesco, é uma extensão da liberdade de expressão. Garantido esse direito, jornalistas tornam-se aptos a informar a sociedade como acharem condizente, sem filtros prévios ou simultâneos, devendo se mirar apenas em códigos de ética específicos. Essa abordagem foi defendida posteriormente por Pieranti e Zouain (2006). A liberdade de imprensa pode ser resguardada, na prática, por instrumentos específicos, como a "cláusula de consciência". Em países onde vigora essa proteção legal, jornalistas podem se recusar a cumprir ordens ou divulgar notícias com determinado viés, se julgarem que essas atitudes ferem sua honra ou não refletem a veracidade dos fatos. Em alguns casos, há proibição explícita de demissão de jornalistas com base nas crenças que professam. No Brasil, não vigora nenhum desses dispositivos legais.

Notamos, então, que para que seja garantida a liberdade de imprensa não basta, apenas, a vigência de leis que a assegurem, ainda que elas sejam essenciais, e sua garantia por parte do Estado. A liberdade de imprensa está não só associada ao manancial legal vigente em cada país, como também à organização das empresas jornalísticas, ao dia-a-dia dos profissionais dessa área e, principalmente, à relação entre os interesses privados de empresários e anunciantes e a defesa do interesse público, (que deveria ser) feita pelos jornalistas.

Passados mais de 20 anos da elaboração do relatório da Unesco, pouco foi produzido no sentido de aprofundar as discussões acerca de parâmetros para as políticas públicas para as comunicações. Pela relação que a área tem com a democracia, não se aplicam modelos-padrão que consideram apenas o resultado das políticas e os investimentos feitos. Especificamente a garantia da liberdade de expressão, alicerce das informações a serem transmitidas, não se restringe à elaboração de políticas para esse fim, consolidando-se de forma lenta e gradual. Políticas para restringi-la podem ser implementadas com sucesso razoável (em desacordo com os princípios democráticos discutidos anteriormente) e em curto espaço de tempo. Cabe agora considerar, no contexto brasileiro, as duas dimensões existentes das políticas públicas para as comunicações, tal como apresentadas no relatório da Unesco. 


\section{A infra-estrutura para as comunicações no Brasil}

Era incipiente a infra-estrutura brasileira para as comunicações até 1964. De acordo com Haroldo Corrêa de Mattos (1984), ministro das Comunicações no governo de João Figueiredo, o serviço telefônico era oferecido por mais de 800 concessionárias locais que não dispunham de homogeneidade técnica; havia, em média, menos de dois telefones por 100 habitantes no país; a radiodifusão era local ou regional; e não havia registro completo das emissoras brasileiras de rádio e de televisão.

A partir de 1964, com a ascensão dos militares ao poder, consolidava-se o corolário, conforme frisa Mattos (1984), de que as comunicações tinham, como objetivos, a promoção da integração e do desenvolvimento nacionais; a difusão da informação, educação e cultura; e a garantia da segurança nacional. O know-how para atingir esses objetivos vinha sendo desenvolvido nas unidades militares desde a década de 1920, com o preparo de oficiais especialistas na área de telecomunicações, principalmente no que se refere à telefonia. Esse esforço levou militares a postos de destaque na estrutura de regulação das telecomunicações antes de 1964 e foi mote para a criação, em 1959, da arma de comunicações do Exército brasileiro (Mathias, 1999).

Não bastaria o preparo técnico dos militares, porém, sem uma reforma nas estruturas responsáveis pela regulação das comunicações. Essa havia sido iniciada em 1962 com a promulgação do Código Brasileiro de Telecomunicações. Como lembra Pieranti (2005), tratou-se de momento ímpar de demonstração da força dos empresários ligados à radiodifusão, ora reunidos na Associação Brasileira de Emissoras de Rádio e de Televisão (Abert), recémcriada. Por pressão deles, o Poder Legislativo federal derrubou cada um dos 52 vetos estabelecidos pelo presidente da República, João Goulart, ao projeto de lei para a criação do Código Brasileiro de Telecomunicações.

Em 1967, já durante o regime militar, foi criado o Ministério das Comunicações, cujo posto máximo, à exceção do que ocorreu no governo de Costa e Silva, foi sempre ocupado por um militar até o fim do regime. Nas décadas de 1960 e 1970, o Estado montou empresas estatais para capitanear os investimentos nessa área e modificou o aparato tecnológico voltado à transmissão de dados. Data dessas décadas a criação da Embratel em 1965, da Telebrás em 1972 e da Radiobrás em 1975, por meio das quais foi possível consolidar e ampliar a comunicação via satélite e as linhas de transmissão de dados, viabilizar a TV em cores e aumentar a capilaridade da radiodifusão e da telefonia nacionais. Com essas inovações, tornou-se possível a integração de pontos remotos do país, contribuindo para a difusão da imagem ansiada pelos militares. 
Às empresas privadas coube a modernização de seu próprio aparato técnico, em consonância com os investimentos em infra-estrutura feitos pelo Estado. As empresas que não se adequaram aos novos empreendimentos do regime viveram fase de declínio, ocaso e, por último, falência. Essas mudanças se tornam mais claras no âmbito da televisão: findo o regime militar, era amplamente diferente a ocupação do espectro de freqüências no Brasil — em parte decorrente, segundo Pieranti (2004), da inadequação das empresas, por vezes com estruturas administrativas arcaicas, em parte graças a pressões do regime. No mais das vezes, essas causas corriam em paralelo, como, por exemplo, no caso da Rede Tupi. Incapaz de se adequar às mudanças e imersa em dívidas, a rede de TV pioneira e outrora toda poderosa da mídia brasileira teve suas concessões cassadas em diversas unidades da federação.

Em parceria com a iniciativa privada, notadamente com novos expoentes do empresariado dispostos a investir na radiodifusão sem ter experiências anteriores nessa área, o Estado proporcionou uma expansão das emissoras de rádio e de televisão. Segundo dados confrontados do IBGE e de Euclides Quandt de Oliveira (1978), ex-ministro das Comunicações, em 1978 eram 910 emissoras de rádio em ondas médias, um crescimento de 42,9\% se comparadas com as 637 de 1961; 213 emissoras de rádio FM contra 26 em 1961 (crescimento de 719,23\%); e 115 geradoras de TV contra 23 de 1961 (crescimento de 500\%). Para o Estado, a expansão das emissoras distribuídas, não raro, para políticos e empresários aliados, permitia, em tese, atingir os objetivos listados anteriormente. Para a iniciativa privada, relacionada a políticos no âmbito regional, preenchia-se lacuna histórica e escancarava-se oportunidade em mercado até então incipiente. Ainda que o regime militar tenha proporcionado a criação das emissoras educativas estatais tanto no âmbito federal quanto no estadual, criando, inclusive, legislação para esse fim, a expansão da radiodifusão foi alicerçada sobre base eminentemente privada.

Aos poucos o Estado brasileiro, já sob os auspícios democráticos, diminuiu os investimentos em infra-estrutura e as políticas que visavam ao atendimento das necessidades técnicas das comunicações. O lançamento dos satélites BrasilSat-I e BrasilSat-II, em 1985 e 1986, foi o último suspiro da política do regime militar voltada à modernização da infra-estrutura para as comunicações, contrastando com a diminuição dos investimentos nos anos subseqüentes.

Em um primeiro momento, os investimentos feitos ainda durante o regime militar foram suficientes para atender às demandas, mas, na década de 1990, mostrava-se flagrante a defasagem da infra-estrutura nesse campo, principalmente no que se refere à telefonia, setor alvo de mudanças por parte 
do governo de Fernando Henrique Cardoso. Esse governo dividiu as empresas telefônicas estatais por regiões e privatizou-as. Para isso, separou radiodifusão, que permanecia regulada pelo Código Brasileiro de Telecomunicações de 1962 e legislação posterior, de telefonia, então regulada pela nova Lei Geral das Telecomunicações de 1997. Para que o Estado mantivesse mecanismos para a regulação da telefonia e da transmissão de dados, criou-se a Agência Nacional de Telecomunicações (Anatel) em 1997, responsável também pela regulação da TV por assinatura. Trata-se de autarquia especial que, legalmente, é independente do ponto de vista administrativo e autônoma do ponto de vista financeiro, comandada por dirigentes com mandato fixo e estabilidade e não subordinada hierarquicamente a nenhum órgão. Com funções principalmente no setor de telefonia, a Anatel é responsável, ainda, por administrar o espectro de radiofreqüências e estabelecer as condições para a obtenção e transferência de outorgas nos serviços que regula.

Característica essencial a esse modelo de regulação é a independência das agências. Nelas, o Poder Executivo não deve interferir politicamente, caracterizando uma instância pretensamente neutra em relação aos atores interessados, em que as decisões são tomadas levando-se em consideração fundamentalmente aspectos técnicos. Essas são premissas radicalmente opostas ao observado especificamente no campo das comunicações no Brasil, marcado por práticas como clientelismo e pela influência dos atores político-partidários, que se fortaleceram com o modelo de expansão da radiodifusão adotado durante o regime militar e intensificado no raiar da Nova República, como se verá adiante. Referindo-se a esse cenário e à criação da Anatel, Ramos (2004:9) conclui:

tentou-se criar um ente estranho, despolitizado, "técnico e apartidário", como se fosse possível separar política de governo de política de agência "independente"; separar política executiva de política regulatória. Ao que consta de especulações do período, essa separação deveria ter sido ainda mais radical com a extinção do Ministério das Comunicações, fundido a um genérico Ministério da Infra-estrutura, deixando para a Anatel a condução quase total da política setorial.

Afastou-se o Estado dos investimentos em telefonia, repassando-os à iniciativa privada, e criou uma instância de regulação permeada por empresariado e sociedade civil, mantendo a radiodifusão regulada em conformidade com os princípios consagrados ainda na década de 1960. Em tese, enfraqueceu o Ministério das Comunicações, diminuindo suas funções e restringindo sua área de atuação. A perda de funções do ministério, ocorrida durante a gestão de Sergio 
Motta, chegou a ser entendida, como ressaltado por Ramos (2004), como parte de uma ampla reestruturação das comunicações, que culminaria no fim do ministério e na aceitação da Anatel como entidade responsável pela política para o setor (Prata, Beirão e Tomioka, 1999). Motta faleceu e, passados 11 anos da criação da Anatel, o Ministério das Comunicações não só não foi fechado, mas continua como posto cobiçado no primeiro escalão do governo federal.

\section{A regulação da liberdade de expressão no regime militar}

A outra dimensão das políticas públicas para as comunicações, de acordo com o relatório da Unesco (1983), remete ao grau de liberdade de expressão e ao conteúdo informacional difundido pelos meios de comunicação de massa. Trata-se, portanto, de política que não depende da disponibilidade de recursos financeiros, mas de diretrizes e premissas claras quanto à regulação dos direitos fundamentais e dos preceitos democráticos.

A conexão entre manancial legal e garantia da liberdade de expressão (ou falta dela) ficou clara já nos primeiros anos do regime militar. Podemos questionar, em contrapartida, a necessidade de apego a normas legais por parte de um regime autoritário. Smith (2000), no entanto, demonstra que o apreço às leis - ainda que autoritárias em sua essência e passíveis de descumprimento no dia-a-dia - era característica comum aos presidentes militares brasileiros. Tratava-se, segundo a autora, de buscar, no campo legal, legitimidade para governar o país e figurar como chefes de um Estado democrático.

Uma das primeiras incursões dos militares no campo da legislação brasileira referente às comunicações foi o Decreto-Lei no 236 de 1967, cujo maior mérito foi o estabelecimento de limites para a posse de emissoras de radiodifusão. Além disso, tratava-se de documento legal marcado já por um grau de autoritarismo que iria aumentar na legislação brasileira nos anos seguintes, como reflexo do endurecimento do regime militar nos mais diversos setores. Tornou-se passível de punição, de acordo com esse decreto, o uso de emissoras de rádio e televisão para incitar a desobediência às leis, ultrajar a honra nacional, fazer propaganda de guerra ou de processos de subversão, ofender a moral, insultar os poderes da República e colaborar na prática de rebeldia, entre outros. Note que esses são conceitos amplos, passíveis de interpretação igualmente ampla e adaptáveis a grande parte das notícias veiculadas pelos meios de comunicação.

A Lei no 5.250 de 1967, conhecida como Lei de Imprensa, também estabeleceu parâmetros coercitivos. Se, em seu art. 1으, afirma que é livre a mani- 
festação do pensamento e a difusão de idéias, logo no caput do mesmo artigo é estabelecida a proibição de propagandas de guerra e de processos de subversão da ordem. A Lei de Imprensa estabelece punições, parâmetros para definição de responsáveis pelas matérias jornalísticas e do direito de resposta e obrigatoriedade de registro para publicações impressas (e, conseqüentemente, a criação da categoria "publicações clandestinas"). No mais, a Lei de Imprensa reafirma que apenas brasileiros natos podem ser donos e responsáveis pela orientação ideológica das empresas jornalísticas, diretriz em consonância com as demais regulamentações do setor. Complementando a matéria regulada pela Lei de Imprensa, o Decreto-Lei no 972 de 1969 estabeleceu prazos e condições para a obtenção de registro de jornalista profissional e caracterizou a prática da profissão.

Além desses marcos referentes à radiodifusão e à imprensa criados no regime militar, um conjunto de leis destinadas à sociedade civil de uma forma geral restringiu a liberdade de imprensa e a manifestação de idéias no Brasil pós-1964. Em dezembro de 1968 o regime militar decidiu estancar as crescentes contestações à situação política do país, manifestadas pela sociedade civil em protestos e passeatas e por políticos de oposição em seus discursos, com um instrumento legal já conhecido - o Ato Institucional. Já eram quatro os AIs outorgados desde 1964, o último em dezembro de 1966. A menção à sigla lembrava punições e reformas políticas.

O texto do AI-5 tornou-se conhecido na noite de 13 de dezembro de 1968. Estava mantida a Constituição Federal de 1967, acrescida das mudanças presentes no novo Ato Institucional. Com base nele, o presidente da República poderia decretar o recesso do Congresso Nacional e de assembléias legislativas, intervir no governo de estados e municípios, cassar e suspender direitos políticos, decretar e prorrogar o estado de sítio e confiscar os bens de funcionários públicos corruptos. Ficavam suspensas garantias como vitaliciedade e estabilidade e, em crimes políticos contra a Segurança Nacional, o habeas corpus. No que tange à imprensa, essas restrições significavam que jornalistas enquadrados em crimes previstos na Lei de Imprensa, cujos critérios eram fluidos e passíveis de múltiplas interpretações, poderiam ter seus direitos políticos suspensos e cassados e, se presos, não teriam direito a habeas corpus. $\mathrm{O}$ art. 9o do ato abria prerrogativa, ainda, para a decretação de censura, ao facultar ao Poder Executivo a possibilidade de baixar atos complementares visando à defesa do status quo vigente.

Os crimes contra a Segurança Nacional foram redefinidos quase 10 meses depois. Em setembro de 1969, entrou em vigor o Decreto-Lei oㅜ 898, conhecido como Lei de Segurança Nacional, que revogou legislação similar 


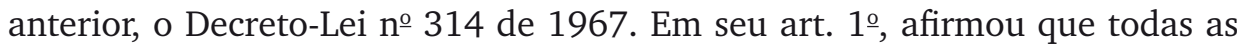
pessoas são responsáveis pela Segurança Nacional, estando todos, implicitamente, submetidos aos ditames previstos no documento. Os crimes e punições previstos na lei são regulados por 47 artigos. Destacam-se entendimentos com outros países para prejudicar a soberania nacional; sabotagem de instalações militares; propagandas subversivas; espionagem em proveito de outro país; divulgação de fato ou notícia falsa com o intuito de criar conflito entre autoridades e a sociedade civil; destruição de símbolos nacionais; estímulo à guerra revolucionária ou subversiva; roubo de bancos com qualquer finalidade; subversão da ordem; promoção de greve; ofensa da honra de autoridades; e criação de organizações paramilitares, entre outros. As penas, dependendo do crime, variavam de oito meses à morte e os julgamentos poderiam ocorrer em foro militar.

Além de cercear as liberdades individuais e ampliar a possibilidade de punições rigorosas a opositores do regime militar, a Lei de Segurança Nacional apresentou brechas semelhantes aos outros marcos legais estudados. Os termos "segurança nacional" e "subversão" continuavam caracterizados de forma ampla e passível de diferentes interpretações. Eram, na verdade, definidos ao sabor do momento pelas autoridades constituídas.

Para a imprensa, a Lei de Segurança Nacional representava um perigoso cerceamento. A liberdade de expressão, já comprometida pelas circunstâncias, tornava-se ainda mais frágil com a possibilidade de ser encarada como propaganda subversiva ou tentativa de confrontar sociedade e governo. A possibilidade de aproximar, por meio legal, jornalistas no cumprimento de suas funções, críticos do regime e integrantes de grupos guerrilheiros era propositalmente perigosa, visto que associava um dos pilares das democracias modernas, ou seja, a imprensa independente e fiscalizadora do poder público, ao conceito de "subversão" difundido pela propaganda governamental. Ao abarcar esses três atores em uma mesma lei, o regime militar estabeleceu sobre a imprensa a desconfiança constante e atraiu para si, em tese, o poder de atribuir confiabilidade ao noticiário diário. Se a imprensa podia ser associada à "subversão", era melhor que a população se mantivesse vigilante e confiasse só na versão oficial, apresentada pelos defensores da segurança nacional.

A rápida análise das quatro leis mencionadas demonstra a diversidade de formas disponíveis para a punição a jornalistas críticos ao regime. A tarefa mais difícil não seria constatar uma irregularidade - seria, dado o amplo leque legal existente, não enquadrar os opositores em nenhum crime. $\mathrm{O}$ olhar vigilante sobre a "subversão" e suas diferentes formas de manifestação estabelecia, na prática, que todos eram virtualmente culpados até prova em 
contrário. Estava configurada a inversão na lógica jurídica: tratava-se então de provar inocência, dia após dia.

A legislação existente colocou jornalistas, ainda, em outro patamar. Os tradicionais crimes de imprensa - calúnia, injúria e difamação — não atentavam mais apenas contra pessoas, mas, às vezes, contra a segurança nacional, ganhando importância distinta. Ofendidos e segurança nacional podiam, então, confundir-se.

Faltava, ainda, regulamentação precisa sobre uma prática. Os crimes e punições estavam claros, mas ainda não havia regulamentação para prevenir supostos delitos cometidos pela imprensa e evitar os transtornos decorrentes desses. Em outras palavras, faltava respaldo legal para o exercício da censura aos meios de comunicação de massa e à prática jornalística. A partir de 1970, com a promulgação do Decreto-Lei no 1.077, não faltava mais. O documento legalizava a censura, comum no país há alguns anos. Seria essa a principal política do regime militar voltada à difusão de informações.

Eram diversas as técnicas usadas pelas instâncias de poder responsáveis pela censura. A mais comum delas, durante a década de 1970, foi recados transmitidos por bilhete ou por telefone às redações. Quase sempre anônimos, vinham acompanhados de expressões como "por ordem superior" e "está proibido" (Smith, 2000). Em poucos casos esclareciam de quem partia a ordem, às vezes atribuída ao ministro da Justiça, às vezes a autoridades policiais ou militares. Chegavam a ser fonte de informação para jornalistas: ocultada a informação graças ao medo imposto aos canais de comunicação, eram os bilhetes que traziam, ao proibir, detalhes dos fatos.

Havia lógica na forma de distribuição dos bilhetes. Anônimos, não eram emitidos, na prática, por ninguém especificamente. Era difícil gerarem qualquer reclamação incisiva por parte dos jornalistas, já que eles não sabiam com precisão a quem recorrer. Seus distribuidores eram policiais de patentes inferiores encarregados de cumprir ordens, sem qualquer ingerência nas proibições. Por mais que revelassem a corporação responsável pela ordem, não deixavam claro quem era autor da mesma. Entregues a jornalistas ocupantes de cargos hierarquicamente altos e responsáveis pela produção jornalística do periódico, os bilhetinhos atingiam seu alvo e cumpriam o objetivo a que se dispunham, ou seja, a não-veiculação de determinada informação. Não havia possibilidade de um determinado periódico acusar o não-recebimento do bilhete, já que cabia a quem o recebia assinar um recibo. Anônimos, enfim, transmitiam um recado claro: a ordem deveria ser cumprida sem hesitação.

Censura prévia e proibições por meio de avisos impediam a divulgação de material prejudicial ao regime militar, enquanto ameaças de processos a 
jornalistas com base na Lei de Imprensa e na Lei de Segurança Nacional estabeleciam o temor nas redações. Os mecanismos oficiais de punição, porém, pouco foram usados, em parte devido ao cumprimento das proibições pela imprensa. Kucinski (1998) afirma que foram apenas 15 os jornalistas processados por crimes de imprensa no período, na maior parte das vezes graças a textos publicados em jornais do interior do país.

À censura, legalizada e oficial, somaram-se outros procedimentos concebidos no âmbito do Estado. O corte de publicidade proveniente de empresas estatais, como retrata Smith (2000), ajudou a sufocar financeiramente empresas jornalísticas que se indispuseram com o regime. Outro procedimento foi a apreensão de periódicos. Em 1977, a Polícia Federal apreendeu oito edições da Tribuna da Imprensa e, entre 1977 e 1982, foram apreendidas 15 edições de Repórter. As apreensões significavam duplo prejuízo: as perdas eram financeiras, já que se gastava com a publicação dos periódicos que não eram vendidos, e de credibilidade junto aos leitores, pois os jornais sumiam das bancas sem que os leitores fossem previamente avisados. Os métodos coercitivos e punitivos oficiais e o emprego deles não pareciam ser suficientes para setores das Forças Armadas. Grupos de extrema-direita atacaram, na segunda metade da década de 1970 e início da de 1980, pelo menos, 31 alvos considerados subversivos (Argolo, Ribeiro e Fortunato, 1996), entre eles redações de periódicos, bancas de jornal, casas de jornalistas e associações representativas de classe.

\section{A nova compreensão da liberdade de expressão}

A censura e a coerção explícita, comuns durante o regime militar, foram rechaçadas pela Constituição Federal de 1988, já sob os auspícios da Nova República. Consagrada como direito fundamental no art. $5^{\circ}$ do documento, a liberdade de expressão foi reafirmada no art. 220, o primeiro do Capítulo V do Título VIII, referente à comunicação social. O art. 220 reafirma não só a garantia da liberdade de expressão e de difusão de informações, como impede o estabelecimento de mecanismos legais que possam restringi-las. Fica assegurada, também, a possibilidade de publicação de meios de comunicação impressos, sem que o editor dependa de licença de qualquer autoridade, o que aumentaria, em tese, a independência dessa mídia específica, principalmente com o veto à incidência de impostos provenientes de qualquer esfera pública sobre livros, jornais, periódicos e o papel destinado à impressão deles.

É inegável o avanço que representa a Constituição Federal de 1988 em comparação às suas antecessoras. Nunca uma Carta Magna garantira, com ta- 
manha clareza, a liberdade de expressão, encarada como direito fundamental, em nítida oposição ao caráter que lhe fora reservado pelo regime militar e em consonância com interpretações democráticas desse conceito, como a feita pela Unesco. Além da garantia dessa liberdade, a Constituição Federal podou dois tradicionais mecanismos de pressão da imprensa por parte do Estado: a elevação de impostos (ou criação deles) sobre periódicos e a possibilidade de cancelamento da licença das publicações.

A garantia dessas liberdades não foi acompanhada, porém, de mecanismos de regulação. As liberdades de expressão e de imprensa são não raro interpretadas, como lembra Arbex Júnior (2001), como o direito que os donos das empresas de comunicação têm de escolher o que será veiculado e publicado. A forma como a liberdade de expressão é afirmada no principal documento legal do país e a inexistência, no art. 220, de mecanismos de regulação a serem operados pelo Estado, têm funcionado, para Castro (2002:124), "como uma negação dos empresários à necessidade de estabelecer limites". Criado o fosso legal, tornam-se mais difíceis para o Estado a formulação e a implementação de políticas que se refiram ao conteúdo informativo dos meios de comunicação, já que medidas que incidem contra os interesses do empresariado correm o risco de ser prontamente taxadas de inconstitucionais e de estarem violando a liberdade de expressão.

No tocante à posse das emissoras, a política de Estado relativa à distribuição de concessões reforçou, como lembra Motter (1994), dois aspectos estruturais dominantes na radiodifusão brasileira. O primeiro é o predomínio das redes nacionais e comerciais de televisão e de conglomerados de mídia, facilitando a concentração de meios de comunicação sob mesma égide e a formação de oligopólios, o que deve ser repelido de acordo com o art. 220 do texto constitucional. De acordo com pesquisa feita pelo Instituto de Estudos e Pesquisas em Comunicação (Epcom, 2002), as seis principais redes de televisão privadas reuniam 140 grupos afiliados, detentores, por sua vez, de 667 meios de comunicação, divididos entre 294 emissoras geradoras de TV em VHF, 15 em UHF, 122 emissoras de rádio OM, 184 FM, dois OT e 50 jornais e revistas. De acordo com uma atualização parcial dessa pesquisa, feita em 2005 pelo Fórum Nacional pela Democratização das Comunicações (FNDC), as seis principais redes comerciais de televisão teriam 263 emissoras afiliadas de um total de 332 existentes no país (nessa mídia). A concentração dos meios de comunicação no plano nacional, notadamente na mídia televisiva, reduz as possibilidades de afirmação da produção independente e regionalizada, prevista no art. 221 do texto constitucional, já que ela adquire caráter secundário em relação à produção das emissoras cabeça-de-rede, onde há infra-estrutura 
montada e gastos otimizados para o investimento em programação. Como os custos de investimentos semelhantes nas emissoras afiliadas são mais altos que a simples retransmissão da programação produzida nos grandes centros e, ainda assim, altos gastos não são sinônimo de garantia de sucesso da programação, empresários da radiodifusão hesitam em produzir conteúdo próprio. Note-se, ainda, que não há limites para o número de emissoras afiliadas por rede e, conseqüentemente, de área ou de público a ser alcançado por uma programação específica. As redes brasileiras têm caráter realmente nacional, pois cobrem virtualmente todo o território do país.

A segunda tendência estruturante, como assinala Motter (1994), é o aumento de grupos políticos regionais no cenário da radiodifusão, fenômeno conhecido como coronelismo eletrônico. Comumente esses políticos associamse aos grandes empresários da mídia, incidindo nos problemas anteriormente discutidos - concentração dos meios de comunicação e pouco estímulo à produção regional e independente. Há, nesse caso, porém, um agravante. Por mais que os marcos legais sejam imprecisos no que se refere à radiodifusão, há uma evidente burla, pelo menos, ao espírito do legislador. Assim, por mais que a Constituição Federal e o Código Brasileiro de Telecomunicações vedem o exercício de funções diretivas de empresas de radiodifusão por parlamentares, e proíbam que estes mantenham relações formais com aquelas, é comum a posse das emissoras por familiares, amigos e correligionários dos parlamentares, quando não por eles mesmos, principalmente devido à inexistência de uma fiscalização rigorosa e permanente.

Atualmente, a liberdade de imprensa caracteriza-se por seu caráter praticamente desregulado, sem que o Estado consiga estabelecer limites para o conteúdo a ser difundido. Depende esse conteúdo, hoje, basicamente do bom senso dos responsáveis por sua divulgação, confundindo-se, na prática, a liberdade de imprensa com a de empresa. Sem que haja barreiras à censura interna nas redações ou sem que seus profissionais não sejam, de alguma forma, resguardados por cláusulas de consciência e similares, acaba por prevalecer a liberdade de empresa, mediante a qual os donos dos meios de comunicação e os funcionários de sua confiança tornam-se os responsáveis por escolher o que será divulgado. $\mathrm{O}$ interesse público nem sempre é encarado como prioritário.

\section{Considerações finais}

A associação entre comunicações e desenvolvimento, feita pelo relatório da Unesco, enfoca essencialmente o aspecto técnico da primeira como forma de 
promoção do segundo. Sem a necessária infra-estrutura para a transmissão de dados, torna-se mais difícil o acesso dos governos às sociedades, bem como ficam comprometidos os mecanismos para a implementação de políticas públicas e execução de ações provenientes da administração pública. Exemplo claro da ligação entre comunicações e estratégias de desenvolvimento ocorreu durante o regime militar brasileiro, não só pelo discurso que buscava associar os dois termos, como pelas inovações empreendidas no campo tecnológico no sentido de criar e modernizar a infra-estrutura existente no setor. Esse esforço de modernização, com gastos públicos, da tecnologia existente, diminuiu consideravelmente nas décadas posteriores, visto que parte dos gastos foi repassada à iniciativa privada.

A modernização da infra-estrutura compreendeu basicamente os setores de radiodifusão e telefonia, a mídia impressa ficou responsável por seus próprios gastos, e só recebeu verbas públicas na forma de anúncios, essenciais à sua sobrevivência.

É possível perceber, pelo menos, duas diretrizes das políticas públicas para a mídia, no Brasil, durante o período de tempo compreendido neste artigo: o estímulo à expansão da radiodifusão privada vinculada a critérios políticos e a confusão proposital entre liberdade de imprensa e de empresa. O primeiro compreende a avidez do poder público, por vezes legislando e agindo em causa própria, em dividir o espectro de radiofreqüências entre oligarquias regionais. Por um lado, permitiu-se, assim, o desenvolvimento e a expansão do rádio e da televisão nacionais; por outro, utilizou-se um bem público (o espectro de freqüências) para o atendimento de interesses privados e a troca de favores políticos.

A solução para esse problema passaria obrigatoriamente por uma legislação que estabelecesse limites rígidos para a ação do poder concedente, relacionando-a a princípios como a democratização das comunicações. Seria necessário, enfim, evitar a vinculação da mídia eletrônica a interesses privados de grupos específicos. Além disso, seria fundamental a ampliação do investimento estatal em uma rede de emissoras pública e educativa, com um modelo de programação que se contrapusesse ao da radiodifusão comercial e privada, estabelecendo alternativas a ele.

Já o segundo alicerce dessas políticas pressupõe uma predisposição do Estado em evitar a regulação de um direito fundamental, a liberdade de expressão, prevista no texto constitucional. Desregulada, tornou-se, na prática, confundida com a liberdade de empresa, já que operacionalizada pelo empresariado. Durante o regime militar, quando o Estado optou por regular esse direito, descaracterizou-o e anulou-o. Seja pela sensibilidade natural 
do tema, seja pela falta de compromisso dos atores públicos, no Brasil essa liberdade só foi cerceada e jamais regulada como direito fundamental de toda a sociedade. O Estado brasileiro termina, na prática, por esquivar-se da regulação dos meios de comunicação, evitando a formulação de políticas públicas nesse sentido, e deixando a difusão de informações a critério da iniciativa privada.

Uma possibilidade de ação nesse âmbito envolveria uma maior participação da sociedade civil, já que é ela, em última análise, a principal interessada na garantia dos direitos fundamentais. Essa maior participação dependeria, contudo, de uma reformulação dos marcos legais existentes, o que parece ser inviável no presente, dados os interesses já consolidados e a correlação de forças no âmbito público, favorável à parceria entre empresariado e parte do Congresso Nacional.

Por fim, cabe questionar a aplicação do postulado de independência da mídia. Funcionando em conformidade com a lógica empresarial, carecendo de regulação sistemática e enfática e permitindo a conjugação simultânea entre interesses privados e públicos, é de se esperar que os meios de comunicação de massa no Brasil reflitam todos esses problemas constantes na estrutura de regulação que ora incide sobre o setor, pecando em respeitar princípios apontados como essenciais aos meios de comunicação, como a independência.

\section{Referências bibliográficas}

AMORIM, José Salomão David. Comunicação e transição no Brasil: propostas de mudanças de políticas de comunicação e sua viabilidade. Textos de Cultura e Comunicação, Brasília: Nicom, n. 12, 1986.

ARBEX JÚNIOR, José. Showrnalismo: a notícia como espetáculo. São Paulo: Casa Amarela, 2001.

ARGOLO, José; RIBEIRO, Kátia; FORTUNATO, Luiz Alberto. A direita explosiva no Brasil. Rio de Janeiro: Mauad, 1996.

CAMPANHOLE, Adriano; CAMPANHOLE, Hilton Lobo. Constituições do Brasil. São Paulo: Atlas, 1989.

CASTRO, João Caldeira Brant Monteiro de. Políticas nacionais de radiodifusão (1985-2001) e espaço público. 2002. Trabalho de Conclusão de Curso (monografia)

— Escola de Comunicações e Artes, USP, São Paulo, 2002. ms. 
CONGRESSO NACIONAL. Concentração da mídia: debates no Conselho de Comunicação Social, 2004. Disponível em: <www.senado.gov.br/comissoes/_ccs/docs. asp>. Acesso em: 23 jun. 2004.

COSTA, Sylvio; BRENER, Jayme. Coronelismo eletrônico: o governo Fernando Henrique e o novo capítulo de uma velha história. Comunicação \& Política, Rio de Janeiro, v. 4, n. 2, p. 29-53, 1997.

CURADO, Isabela. Pesquisa historiográfica em administração: uma proposta mercadológica. In: ENCONTRO NACIONAL DA ASSOCIAÇÃO NACIONAL DOS PROGRAMAS DE PÓS-GRADUAÇÃO EM ADMINISTRAÇÃO, 25., 2001, Campinas. Anais... Campinas, São Paulo: Anpad, 2001.

DAHL, Robert. Sobre a democracia. Brasília, DF: UnB, 2001.

EPCOM. Quem são os donos da mídia. Carta Capital, São Paulo, ano VIII, n. 179, 6 mar. 2002.

FOX, Elizabeth; WAISBORD, Silvio. Latin politics, global media. In:

(Orgs.). Latin politics, global media. Austin: University of Texas Press, 2002.

HERMAN, Edward S.; CHOMSKY, Noam. A manipulação do público: política e poder econômico no uso da mídia. São Paulo: Futura, 2003.

KOVACH, Bill; ROSENSTIEL, Tom. Os elementos do jornalismo: o que os jornalistas devem saber e o público exigir. São Paulo: Geração Editorial, 2003.

KUCINSKI, Bernardo. A síndrome da antena parabólica. São Paulo: Perseu Abramo, 1998.

KUNCZIK, Michael. Conceitos de jornalismo: Norte e Sul. São Paulo: EdUsp, 2002.

LIMA, Venício A. Globo e política: “tudo a ver”. In: BRITTOS, Valério Cruz; BOLAÑO, César Ricardo Siqueira (Orgs.). Rede Globo: 40 anos de hegemonia e poder. São Paulo: Paulus, 2005.

MARCONDES FILHO, Ciro. O Estado como meio de comunicação. Comunicação \& Política, Rio de Janeiro, ano XI, n. 17, p. 31-34, 1991.

MARTINS, Paulo Emílio Matos. A reinvenção do sertão: a estratégia organizacional de Canudos. Rio de Janeiro: FGV, 2001.

MATHIAS, Suzeley Kalil. Forças Armadas e administração pública: a participação militar nas comunicações e na educação. 1999. Tese (Doutorado) — Universidade Estadual de Campinas, Campinas. ms.

MATTOS, Haroldo Corrêa de. Política das comunicações. Rio de Janeiro: Escola Superior de Guerra, 1984. ms. 
McCHESNEY, Robert W. Rich media, poor democracy: communication politics in dubious times. Chicago: University of Illinois Press, 1999.

MOTTER, Paulino. O uso político das concessões das emissoras de rádio e televisão no governo Sarney. Comunicação \& Política, Rio de Janeiro, v. 1, n. 1, p. 89-116, 1994.

OLIVEIRA, Euclides Quandt de. Política nacional de comunicações. Rio de Janeiro: Escola Superior de Guerra, 1978. ms.

PIERANTI, Octavio Penna. Políticas públicas para radiodifusão e imprensa: dos generais militares ao governo Lula. In: ENCONTRO DE ADMINISTRAÇÃO PÚBLICA E GOVERNANÇA, 1., 2004, Rio de Janeiro. Anais... Rio de Janeiro: Anpad, 2004. 1 CD-ROM.

. Políticas públicas para radiodifusão e imprensa: ação e omissão do Estado no Brasil pós-1964. 2005. Dissertação (Mestrado) — Escola Brasileira de Administração Pública e de Empresas, Fundação Getulio Vargas, Rio de Janeiro.

; ZOUAIN, Deborah Moraes. Liberdade de imprensa e administração pública brasileira: relação de dependência ou independência? In: MARTINS, Paulo Emílio Matos; PIERANTI, Octavio Penna (Orgs.). Estado e gestão pública: visões do Brasil contemporâneo. Rio de Janeiro: FGV, 2006.

PRATA, José; BEIRÃO, Nirlando; TOMIOKA, Teiji. Sérgio Motta: o trator em ação. São Paulo: Geração Editorial, 1999.

RAMOS, Murilo César. Agências reguladoras: a reconciliação com a política. In: LATIN AMERICAN STUDIES ASSOCIATION, 2004, Las Vegas, Nevada. Anais... Las Vegas, Nevada: Lasa, 2004.

SMITH, Anne-Marie. Um acordo forçado. Rio de Janeiro: FGV, 2000.

SODRÉ, Nelson Werneck. História da imprensa no Brasil. São Paulo: Mauad, 1999.

TUMA, Nicolau. A comunicação social e os objetivos nacionais. Rio de Janeiro: Escola Superior de Guerra, 1972. ms.

UNESCO. Um mundo e muitas vozes: comunicação e informação na nossa época. Rio de Janeiro: FGV, 1983.

VERGARA, Sylvia Constant. Método de pesquisa em administração. São Paulo: Atlas, 2005.

WHEELER, Mark. Politics and the mass media. Oxford: Blackwell, 1997. 